\title{
Hypovitaminosis D Is Associated with Some Metabolic Indices in Gestational Diabetes Mellitus
}

\author{
Ayobola Abimbola Sonuga ${ }^{a, b}$ Oyebola Oluwagbemiga Sonuga ${ }^{a, b}$ \\ ${ }^{a}$ Department of Biochemistry, Lead City University, Ibadan, Nigeria; ${ }^{b}$ Chemical Pathology \\ Department, University College Hospital, Ibadan, Nigeria
}

\begin{abstract}
What Is It about?
There appears to be a link between serum levels of vitamin D, glucose, insulin, HOMA-IR, inflammatory markers, and trace metal in gestational diabetes mellitus (GDM). However, there is limited knowledge and results are inconsistent on the relationship between vitamin D status and these metabolic markers that are implicated in the pathophysiology of GDM, especially in Nigeria. Therefore, this study assessed how decreased serum levels of vitamin D in GDM can impact negatively on insulin sensitivity, high-sensitivity C-reactive protein, ferritin, and zinc levels and thereby establish the possible role of vitamin D in the pathogenesis of GDM.
\end{abstract}

\section{Keywords}

Hypovitaminosis D · Gestational diabetes mellitus · Glucose $\cdot$ Insulin · Ferritin · Zinc

\begin{abstract}
Background: Gestational diabetes mellitus (GDM), a pregnancy complication, is defined as any degree of glucose intolerance with onset or first recognition during pregnancy. Vitamin $D$ deficiency and insufficiency has recently been recognized as a contributing factor to the pathogenesis of GDM, and this link might be associated with hyperglycemia, insulin resistance, and inflammation, which are implicated in GDM. Objectives: This study aims at investigating the relationship between vitamin $D$, fasting plasma glucose (FPG), insulin, zinc, ferritin, and high-sensitivity C-reactive protein (CRP) in GDM. Method: A case-control study in which 80 women attending the antenatal clinic of University College Hospital (UCH), Ibadan, Nigeria, were recruited; the women were grouped into controls ( 40 nondiabetic pregnant women) and cases (40 pregnant women with GDM). Blood samples were taken at the second trimester, and metabolites were quantified by standard laboratory methods. Student's $t$ test and Pearson correlation were used to compare variables and determine the relationship between variables, respectively. Results: Results showed significant $(p<0.05)$ low levels of serum vitamin D and zinc, and significant $(p<0.05)$ higher levels of FPG and serum insulin, ferritin, and CRP in the GDM group compared to the control group. In the GDM group, a positive weak relationship
\end{abstract}


was observed between vitamin $\mathrm{D}$ and zinc $(r=0.18, p<0.05)$, while vitamin $\mathrm{D}$ was inversely correlated with FPG, serum insulin, ferritin, and CRP $(r=-0.23,-0.21,-0.20,-0.46$, respectively, $p<0.05)$. Conclusion: This study suggests that hypovitaminosis $D$ might be associated with glucose intolerance, insulin insensitivity, and inflammation, which are factors implicated in the development and progression of GDM.

\section{Introduction}

Gestational diabetes mellitus (GDM) is a common pregnancy complication, which is associated with the development of spontaneous hyperglycemia during pregnancy [1]. It is a metabolic disorder first diagnosed in the second or third trimester of pregnancy that is not clearly either preexisting type 1 or type 2 diabetes [2]. A review indicated that the occurrence of GDM in sub-Saharan Africa was 14\% [3] and in the Middle East and North Africa it ranged from 8.4 to $24.5 \%$ [4], and a recent review found the prevalence in West Africa to be about $14 \%$ [5]. Normal pregnancy is characterized by a significant reduction in maternal insulin sensitivity in the second and third trimesters. However, the reduced reserve of $\beta$ cells or their maladaptation to increased insulin demands might result in the development of GDM [6]. Decreased maternal insulin sensitivity, or increased insulin resistance, is the underlying pathophysiology of gestational diabetes, which starts near pregnancy and progresses to the third trimester. HOMA-IR stands for homeostatic model assessment of insulin resistance, which is an important index for the assessment of insulin resistance. Insulin resistance, which is defined as the inability of a defined concentration of insulin to illicit a response of nutrient metabolism at the level of the target tissue [7], is the key to the development of GDM. However, GDM has long- and short-term consequences on the mother's and offspring's health [8]. Some adverse effects on the mother's health include urinary tract infection, higher risk of hypertension and postpartum development of type 2 diabetes mellitus $[9,10]$, and increased risk of GDM in future pregnancies [10]. Effects on infant's health include macrosomia, birth trauma, neonatal jaundice, respiratory distress syndrome, hypoglycemia, hypocalcemia and hyperbilirubinemia shoulder dystocia, cesarean delivery, and birth trauma [10]. Pregnancy complicated by untreated or poorly treated diabetes is associated with high maternal and perinatal mortality. Hence, research aimed at prevention, early diagnosis, and treatment of gestational diabetes is very important. Inflammatory and stress responses mediate insulin resistance [11], and inflammatory mediators play an important role in the development and progression of GDM [3].

C-reactive protein (CRP) is a sensitive marker of inflammation and a classical acute phase reactant in numerous pathologic conditions. Elevated CRP levels have been associated with abnormal metabolic conditions such as insulin resistance, hyperglycemia, type 2 diabetes mellitus, and GDM [12].

A study found that the prevalence of elevated CRP is 28\% in normal pregnant women (controls) and 76\% in women with GDM [4]. Studies conducted on CRP and tumor necrosis factor- $\alpha$ in gestational hyperglycemia showed that during pregnancy, increased CRP levels are associated with insulin resistance, maternal dysglycemia, and GDM, hence CRP is an important marker for early prediction of GDM $[13,14]$.

Zinc is one of the most common trace metals in the human body and it plays an important role in growth, acting as a signaling factor [15]. It is a trace element required for the normal synthesis, storage, and secretion of insulin in pancreatic $\beta$ cells. It has been reported in a recent study that the depletion of zinc negatively impacts insulin sensitivity and glucose tolerance [16]. This metal also stimulates glycolysis, inhibits gluconeogenesis, and plays a 
role in glucose transport in adipocytes. In addition, it has been shown that zinc supplementation improves glucose homeostasis in patients with diabetes [17].

Zinc is important in the regulation of chronic inflammatory status through the reduction of inflammatory cytokines. It is also a vital tool in reducing oxidative stress by participating in the synthesis of antioxidants. Physiological concentration of zinc inhibits the production of reactive oxygen species, such as superoxide anion $\left(\mathrm{O}^{-}\right)$, hydrogen peroxide $\left(\mathrm{H}_{2} \mathrm{O}_{2}\right)$, and radical hydroxyl $(\mathrm{OH})$ as well as peroxynitrite [18]. The direct action of zinc ion on antioxidant proteins and modulation of metallothionein induction establishes its antioxidant properties. Direct antioxidant activity of zinc ions is associated with its binding to thiol groups, thus protecting them from oxidation [19].

Zinc acts as cofactor of antioxidant enzyme copper/zinc superoxide dismutase (SOD1), which is suppressed under zinc-deficient conditions. Zinc also may indirectly affect the activity of other antioxidant enzymes, in particular, zinc supplementation significantly increased glutathione peroxidase activity through modulation of selenium status [20].

Ferritin, the major iron storage protein, is an important protein in iron metabolism [21]. Serum ferritin concentration provides an indirect estimate of body iron stores because it is highly correlated with bone marrow iron. Also, ferritin is a positive acute-phase reactant; its serum concentration is increased in the presence of various acute or chronic disease conditions and chronic inflammation-related diseases [22]. Recent studies among healthy individuals and nonpregnant women have shown positive associations of moderately elevated serum ferritin levels with risk factors for cardiovascular diseases [23]. Studies also showed a significant relation between higher serum ferritin levels and insulin resistance syndrome and risk of type 2 diabetes [24]. In pregnant women, Lao and Ho found that women with iron deficiency anemia had a reduced risk of GDM [25]. It was also found that high serum ferritin and CRP levels are independent risk factors for type 2 diabetes [26, 27]. Therefore, increased serum ferritin level might be associated with increased risk of developing GDM.

Vitamin D is a group of fat-soluble secosteroids found mostly in fish liver oils, fatty fish, mushrooms, egg yolks, and liver. Furthermore, vitamin D can also be produced in the body in the presence of sunlight. Its two physiological active forms are vitamin $\mathrm{D}_{3}$ (cholecalciferol) and vitamin $\mathrm{D}_{2}$ (ergocalciferol). In response to parathyroid hormone, both forms are first hydroxylated in the liver to 25 -hydroxyvitamin $\mathrm{D}(25(\mathrm{OH}) \mathrm{D}$ or calcidiol), and sequentially converted to 1,25-dihydroxyvitamin D (calcitriol) in the kidneys. Vitamin D has traditionally been seen as a regulator of bone mineralization and calcium homeostasis; however, recent findings have unveiled its numerous biological roles [28, 29]. Vitamin D facilitates active calcium absorption in the small intestine by increasing calcium channel and calcium binding protein expression and promotes the maturation of preosteoclasts. Vitamin D is also important in the regulation of gene expression by binding to the vitamin $\mathrm{D}$ receptor; this action can also mediate regulation of glucose metabolism through influencing insulin sensitivity insulin secretion and insulin resistance [29]. Vitamin D deficiency in pregnancy was related to the incidence of GDM and serum 25(OH)D was significantly lower in women with GDM than in those with normal glucose tolerance [30]. A case-control study involving 1,280 women with GDM and 3,438 controls evaluated the association of $25(\mathrm{OH}) \mathrm{D}$ concentrations with risk of GDM. After adjusting for confounding factors, women with low concentrations $(<50.0 \mathrm{nmol} / \mathrm{L})$ of $25(\mathrm{OH}) \mathrm{D}$ displayed a significantly increased risk of GDM and adverse pregnancy outcomes [31].

There appears to be a link between vitamin D, glucose metabolites, inflammatory markers, and zinc in GDM. However, there is limited knowledge and results are inconsistent on the relationship between vitamin D status and these metabolic markers in GDM, especially in Nigeria. Therefore, this study aims at establishing the relationship between the serum levels of vitamin D, insulin, high-sensitivity CRP (hsCRP), ferritin, and zinc in GDM and the likely effects of this association on the complications of GDM. 


\section{Materials and Methods}

\section{Study Design}

This is a cross-sectional study carried out among age-matched pregnant women recruited from the antenatal clinic of the Obstetrics and Gynecology Department, University College Hospital (UCH), Ibadan, Oyo State, Nigeria.

The sample size was calculated using the formula described by Daniel [32]. Therefore, 80 participants aged between 18 and 45 years at their second trimester were recruited for this study and grouped into:

Group A: 40 pregnant non-GDM women (controls).

Group B: 40 pregnant women with GDM (cases).

\section{Selection Criteria}

Participants were selected from the pregnant women attending the antenatal clinic of the Obstetrics and Gynecology Department of University College Hospital (UCH), Ibadan, using a convenient (non-random) sampling technique. They were subjected to an oral glucose tolerance test and grouped into the GDM or non-GDM group according to WHO criteria which states that GDM is diagnosed during the oral glucose tolerance test if one or more of the cutoffs is exceeded (fasting $\geq 95 \mathrm{mg} / \mathrm{dL}$ [5.3 mmol/L], $1 \mathrm{~h} \geq 180 \mathrm{mg} / \mathrm{dL}[10.0 \mathrm{mmol} / \mathrm{L}], 2 \mathrm{~h}$ $\geq 155 \mathrm{mg} / \mathrm{dL}$ [8.6 mmol/L]) while the non-GDM group (controls) were women with normal serum glucose levels $\leq 129 \mathrm{mg} / \mathrm{dL}(7.2 \mathrm{mmol} / \mathrm{L})$.

Blood pressure in $\mathrm{mm} \mathrm{Hg}$, weight, and height were measured, and body mass index (BMI) was calculated as weight in kilograms divided by height in meters squared in all of the pregnant women using a standard analog sphygmometer, weighing balance and meter rule, respectively.

Anthropometric measurements were assessed. Body weight was measured in an overnight fasting status, without shoes and in minimal clothing state, using a bathroom scales to the nearest $0.1 \mathrm{~kg}$. Height was measured using a nonstretched tape measure to the nearest $0.1 \mathrm{~cm}$.

Inclusion Criteria

Pregnant women at their second trimester, aged between 18 and 45 years.

Exclusion Criteria

Presence of thyroid or parathyroid disorder, kidney or liver diseases, cardiovascular disease, or hypertension, taking vitamin D supplements within 6 months prior to the study, and smoking.

\section{Sample Collection}

A total of $10 \mathrm{~mL}$ of venous blood was collected from each participant after being issued the informed consent form; $5 \mathrm{~mL}$ was dispensed into a plain (nonanticoagulant) bottle and allowed for clot retraction, then centrifuged and serum separated, and $5 \mathrm{~mL}$ was dispensed into a fluoride oxalate bottle for plasma glucose estimation. Assay samples were stored at $-20^{\circ} \mathrm{C}$ prior to analysis.

\section{Biochemical Assessment}

Determination of Plasma Glucose

The plasma glucose was measured using the glucose oxidase method as described by Trinder [33] on an automated chemistry analyzer (LandWind C-100 plus).

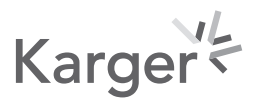


Table 1. Baseline characteristics of glucose-tolerant pregnant women (controls) and women with gestational diabetes (cases)

\begin{tabular}{lcc}
\hline Parameters & Controls $(n=40)$ & Cases $(n=40)$ \\
\hline Age, years & $30.8 \pm 4.1^{\mathrm{a}}$ & $32.6 \pm 4.13^{\mathrm{a}}$ \\
Weight, kg & $61.4 \pm 8.0^{\mathrm{a}}$ & $88.5 \pm 11.64^{\mathrm{a}}$ \\
Height, m & $1.6 \pm 0.04^{\mathrm{a}}$ & $1.6 \pm 0.06^{\mathrm{a}}$ \\
BMI, m ${ }^{2} / \mathrm{kg}$ & $24.2 \pm 2.9^{\mathrm{a}}$ & $32.5 \pm 4.8^{\mathrm{b}}$ \\
SBP, mm Hg & $103.5 \pm 11.8^{\mathrm{a}}$ & $116.5 \pm 8.7^{\mathrm{b}}$ \\
DBP, mm Hg & $70.2 \pm 6.0^{\mathrm{a}}$ & $76.9 \pm 8.7^{\mathrm{a}}$ \\
\hline
\end{tabular}

Values with the same superscript letter within the same column are not statistically different $(p>0.05)$ between the control and case groups, while values with different superscript letters are significantly different $(p<0.05)$. BMI, body mass index; SBP, systolic blood pressure; DBP, diastolic blood pressure.

Determination of Serum Insulin

Serum insulin was measured manually by the enzyme-linked immunosorbent assay (ELISA) method as described by Nakagawa et al. [34] on a microplate reader (StatFax 4200, USA).

Determination of Serum hsCRP

hsCRP was also manually measured using the ELISA method as described by Burtis and Ashwood [35] on a microplate reader (StatFax 4200).

Determination of Serum Zinc Levels

Serum zinc levels were assessed by atomic absorption spectroscopy as described by Molina-López et al. [36].

Determination of Serum Ferritin Levels

The serum ferritin level was determined by using ELISA as described by Garton et al. [37] on a microplate reader (StatFax 4200).

Determination of Serum Vitamin D Concentration

The serum vitamin D level was measured using ELISA as described by Holick and Chen [38] on a microplate reader (StatFax 4200).

Determination of HOMA-IR

The insulin resistance index was calculated using the University of Oxford HOMA calculator software, version 2.2. HOMA-IR was calculated as: [fasting plasma glucose (FPG) $(\mathrm{mmol} / \mathrm{L}) \times$ fasting serum insulin $(\mu \mathrm{IU} / \mathrm{mL})] / 22.5$ [39].

\section{Quality Control}

The quality control samples were run with the participants' samples in each assay batch. The test results were accepted only if the quality control results of the analytical run were in control. The interassay coefficient of variation was determined, being $2.98 \%$ for glucose, $6.47 \%$ for insulin, $9.2 \%$ for hsCRP, $8.41 \%$ for ferritin, $7.41 \%$ for vitamin $\mathrm{D}$, and $2.14 \%$ for zinc.

\section{Statistical Analysis}

Data obtained from this study were subjected to statistical analysis using SPSS version 20.0. The results obtained were grouped and expressed as mean \pm standard deviation.

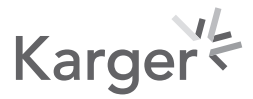


Table 2. Maternal levels of serum vitamin $\mathrm{D}$ and some metabolites in glucose-tolerant pregnant women (controls) and women with gestational diabetes (cases)
Table 3. Pearson correlation between vitamin D, CRP, FPG, insulin, zinc, and ferritin in GDM

\begin{tabular}{lcc}
\hline Parameters & Controls & Cases \\
\hline Vitamin D, ng/mL & $35.3 \pm 9.5^{\mathrm{a}}$ & $26.6 \pm 8.7^{\mathrm{b}}$ \\
FPG, mg/dL & $93.18 \pm 15.4^{\mathrm{a}}$ & $152.15 \pm 28.6^{\mathrm{b}}$ \\
Insulin, pmol/L & $16.39 \pm 7.7^{\mathrm{b}}$ & $30.41 \pm 13.8^{\mathrm{a}}$ \\
HOMA-IR & $1.07 \pm 0.5$ & $1.90 \pm 0.9$ \\
CRP, mg/L & $12.27 \pm 6.8^{\mathrm{a}}$ & $20.13 \pm 4.5^{\mathrm{b}}$ \\
Zinc, $\mu \mathrm{mol} / \mathrm{L}$ & $9.8 \pm 3.9^{\mathrm{a}}$ & $4.04 \pm 1.2 \mathrm{~b}$ \\
Ferritin, ng/mL & $26.62 \pm 8.51^{\mathrm{a}}$ & $40.57 \pm 14.4^{\mathrm{b}}$ \\
\hline
\end{tabular}

Values with the same superscript letter within the same column are not statistically different $(p>0.05)$ between the control and the case groups, while values with different superscript letters are significantly different $(p<0.05)$. FPG, fasting plasma glucose; HOMA-IR, homeostatic model assessment of insulin resistance; CRP, C-reactive protein.

\begin{tabular}{lll}
\hline Parameters & $r$ & $p$ value \\
\hline Vitamin D vs. FPG & -0.23 & 0.00 \\
Vitamin D vs. insulin & -0.21 & 0.04 \\
Vitamin D vs. HOMA-IR & -0.23 & 0.05 \\
Vitamin D vs. hsCRP & -0.46 & 0.01 \\
Vitamin D vs. zinc & 0.18 & 0.00 \\
Vitamin D vs. ferritin & -0.20 & 0.04 \\
\hline
\end{tabular}

The Student $t$ test was used to compare means across the two groups and Pearson correlation was used to establish the relationship between variables. Significant difference was set at $p<0.05[40]$.

\section{Results}

There was no statistical difference $(p>0.05)$ in age, height, and diastolic blood pressure between the two groups. However, weight, BMI, and systolic blood pressure were statistically higher in the GDM group compared to controls (Table 1).

There were significantly lower levels $(p<0.05)$ of serum vitamin D and zinc in the GDM group compared to controls, while the serum levels of FPG, insulin, CRP, and ferritin were significantly higher in the GDM group compared to controls (Table 2).

In the GDM group, there was a significant weak inverse relationship between serum vitamin D levels and FPG, insulin, and CRP, while there was a weak positive relationship between vitamin $\mathrm{D}$ and zinc (Table 3).

\section{Discussion/Conclusion}

This study sought to determine the relationship between vitamin D and some metabolic indices like glucose, insulin, HOMA-IR, ferritin, zinc, and CRP in GDM. BMI and systolic blood pressure were significantly higher in the GDM group compared with controls, similar to 
Fig. 1. A scatterplot showing a weak inverse relationship between vitamin D and FPG.
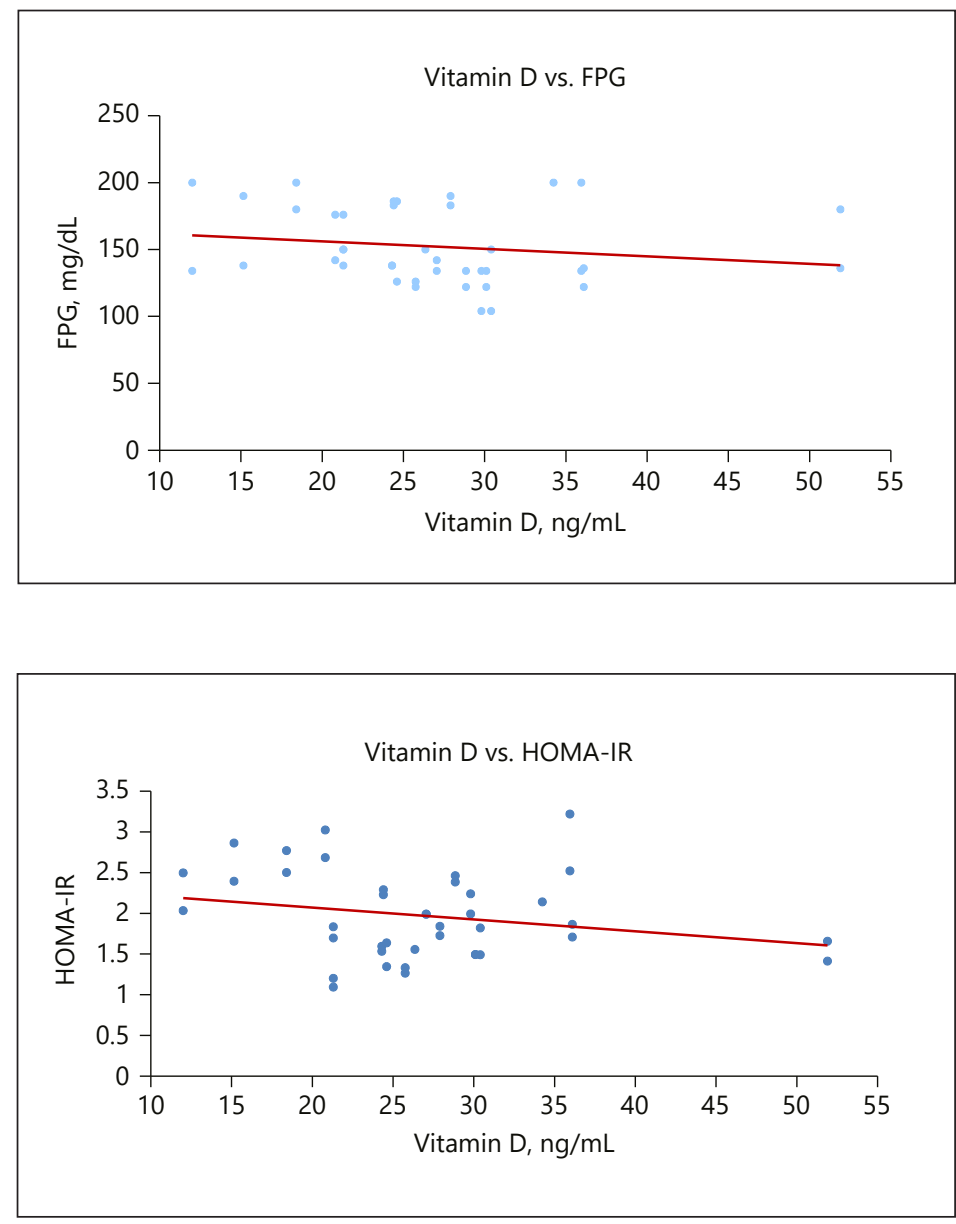

Fig. 2. A scatterplot showing a weak inverse relationship between vitamin D and HOMA-IR. previous studies $[41,42]$. Recent studies show an increased risk of GDM associated with increasing BMI $[43,44]$.

In the present study, we also found a significant lower concentration in serum vitamin $\mathrm{D}$ levels in the GDM group compared to the controls. The hypovitaminosis D observed in the GDM women is similar to that in a previous study reported by Fatemeh et al. [45]. A crosssectional study by Maghbooli et al. [46] also showed that the serum levels of 25(OH)D were significantly lower in the GDM group compared to controls, and the prevalence of GDM was higher in those with severe vitamin D deficiency. Wang et al. [47] indicated a significant difference in serum 25(OH)D concentrations between GDM and pregnant women with normal glucose tolerance even after controlling for age and pre-pregnancy BMI, and reported a $96.25 \%$ prevalence of vitamin D insufficiency and $52.75 \%$ deficiency in the GDM group. There seems to be a link between vitamin D status and pathogenesis of GDM; this connection can be attributed to the role of vitamin D in glucose metabolism, inflammation, and modulation of gene expression for insulin secretion.

FPG concentrations were significantly higher in the GDM group, which is also in accordance with previous studies by $[48,49]$. There was also a significant weak inverse relationship between vitamin D and FPG in GDM as shown in Figure 1. This shows that the hypovitaminosis D observed in the group might be responsible for the higher FPG. Vitamin D mediates an important role in glucose metabolism via the presence of vitamin $\mathrm{D}$ receptors and the expression of $1 \alpha$-hydroxylase enzymes in pancreatic $\beta$ cells along with the presence of a vitamin D response element in the human insulin gene promoter [50]. 
Fig. 3. A scatterplot showing a weak inverse relationship between vitamin D and insulin.
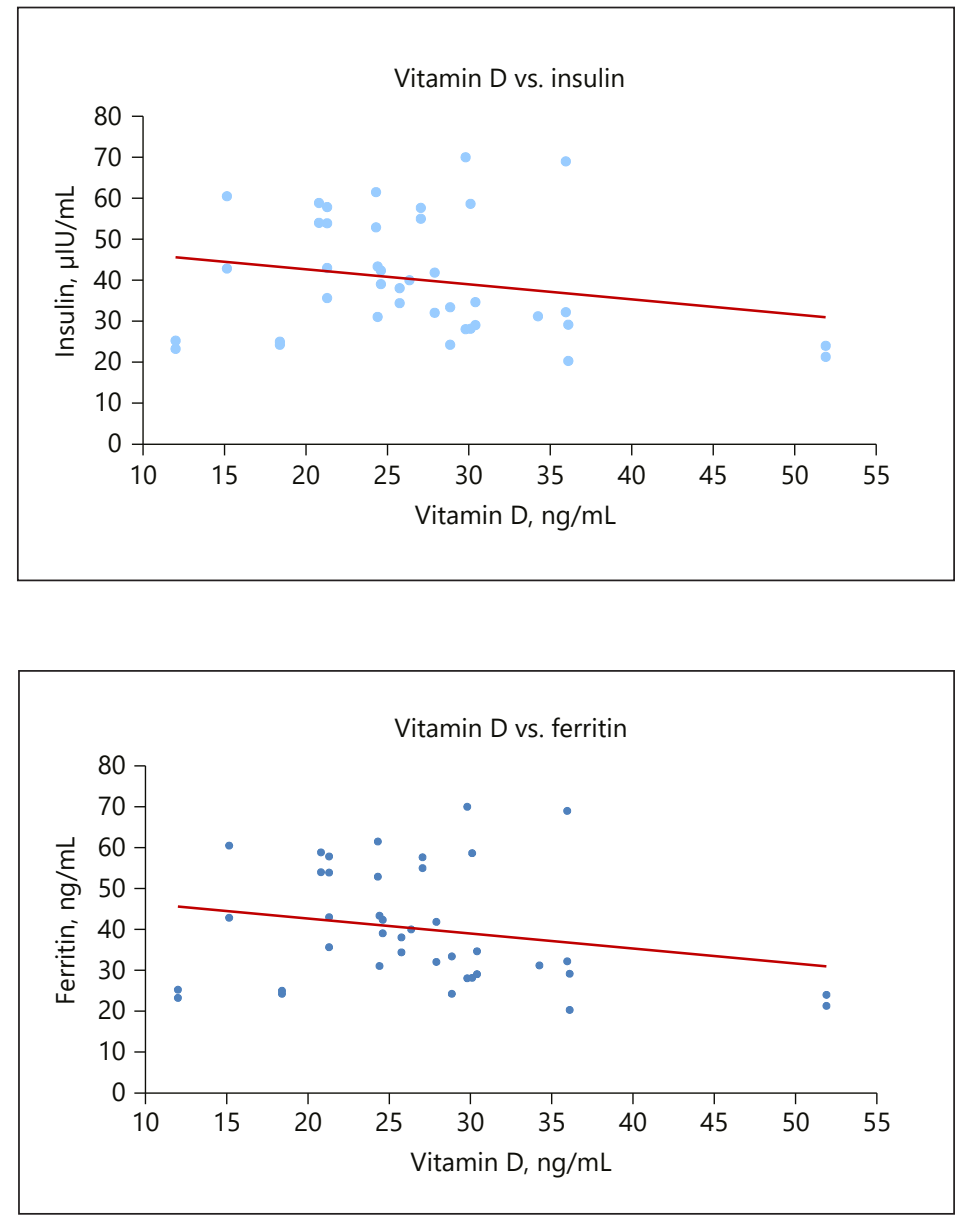

Fig. 4. A scatterplot showing a weak inverse relationship between vitamin D and ferritin.
The serum insulin level was significantly lower in the GDM group compared to the control group, similar to the report of Von Hurst [51], 2010. The insulin resistance index (HOMA-IR) was significantly higher in the GDM group with a mean value of 1.90 and had an inverse relationship with vitamin $\mathrm{D}$, as seen in Figure 2. This result is consistent with previous studies that demonstrated that HOMA-IR assessed at diagnosis of GDM ranged from 1.6 to 2.5 [52]. Causes of insulin resistance are not completely understood; however high maternal weight is associated with insulin resistance during pregnancy. Insulin resistance may be due to increasing secretion of human placental lactogen and other placental secretions or to a systemic inflammation during pregnancy [53]. There was also a weak inverse relationship between vitamin D concentrations and insulin levels in the GDM group, as shown in Figure 3. Vitamin D plays an important role in insulin sensitivity via $\beta$-cell function [54]. The effect of vitamin $D$ on the regulation of pancreatic $\beta$-cell function and insulin secretion could be through intracellular changes in calcium flux through the cell membrane combined with its role in the synthesis and regulation of calbindin, a vitamin D-dependent calcium-binding protein in pancreatic $\beta$ cells. The decrease in calcium flux across cell membranes might result in decreased responsiveness of tissues to insulinmediated intracellular signaling [55].

Vitamin D could also enhance insulin sensitivity by stimulating insulin receptor gene expression, thereby enhancing insulin-mediated glucose transport [56]. Hypovitaminosis D could therefore be an important causative factor in insulin insensitivity and reduced production of insulin by the pancreatic $\beta$ cells, as seen in GDM cases. 
Fig. 5. A scatterplot showing a weak inverse relationship between vitamin D and CRP.

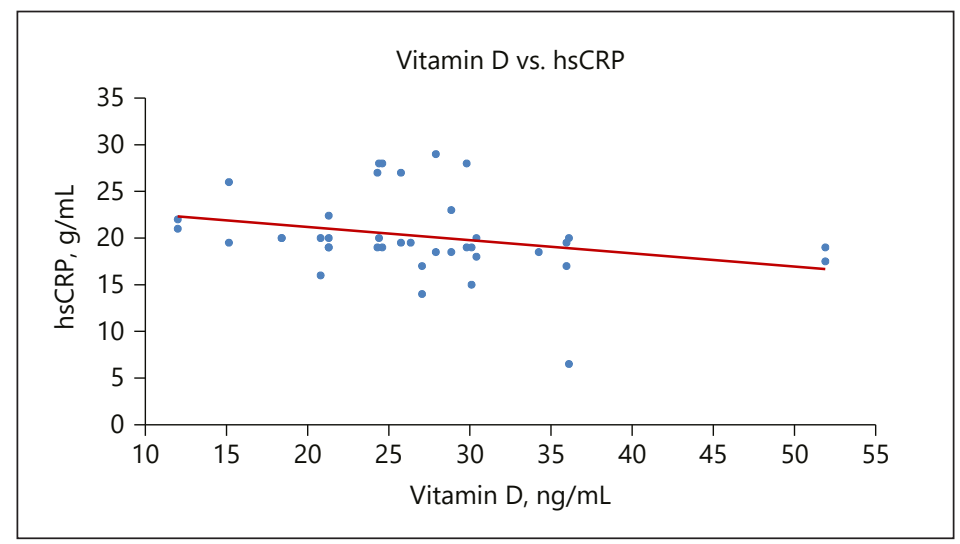

In this study, the GDM group had higher levels of ferritin compared to the control group, this is supported by the study of Chen et al. [57]. Also, a significant weak inverse relationship between vitamin D and ferritin was observed, as shown in Figure 4. Ferritin is important in reflecting body ironstores; infacthigherironstores canbeassociated with insulin resistance in nonpregnant subjects [25]. There is an increasing recognition that iron overload may play a role in insulin resistance at the cellular level. Iron overload impairs the response to insulin in the liver, muscle, and adipose tissue [58]. Excess iron, once stored in the liver, interferes with glucose metabolism, causing hyperinsulinemia via both decreased insulin clearance and impaired insulin signaling. Insulin stimulates the intrahepatic iron accumulation by increasing the uptake of diferric transferrin through an enhanced number of transferrin receptors onto the cell surface while upregulating hepcidin expression directly. Iron has the ability to cause an inhibitory effect of insulin on gluconeogenesis, reducing liver extraction and insulin metabolism. Increasing iron stores leads to peripheral hyperinsulinemia with both liver and muscle resistance [59].

However, data are conflicting regarding whether elevated serum ferritin reflects inflammation or increased iron stores [60]. Ferritin has been recognized as a marker of inflammation, and pregnancy is considered an inflammatory state, and in GDM, inflammation is further increased. In addition, Lao and Ho [25] found that higher hemoglobin ( $>13 \mathrm{~g} / \mathrm{dL}$ ) was an independent risk for GDM and that iron deficiency anemia is associated with a lower risk of GDM. The possible link might be that vitamin D influences iron metabolism and erythropoiesis by its influence on hepcidin via cytokines or independently of changes in pro-inflammatory markers [61]. However, lower levels of pro-inflammatory cytokines and hepcidin increase iron bioavailability for erythropoiesis and hemoglobin synthesis by preventing iron sequestration in macrophages [62]. On the other hand, iron deficiency damages intestinal absorption of fat-soluble vitamins, including vitamin D [63].

Rudnicki and Mølsted-Pedersen [64] reported that supplementation with an active form of vitamin $\mathrm{D}(1,25(\mathrm{OH}) 2 \mathrm{D})$ was associated with a significant decrease of plasma glucose level and possible effect on insulin sensitivity.

Vitamin D may also have a beneficial effect on insulin action either directly or through stimulating the expression of insulin receptors and activating peroxisome proliferator-activated receptors [65].

The increased level of CRP observed in the GDM group in the present study has been reported by Rota et al. [66] and Cruz et al. [67]. Pregnancy is a condition associated with a high degree of inflammation due to increased metabolic activities and oxidative stress in the maternal circulation. However, the inflammation is worsened in GDM and this accounts for the observed increase in the serum level of CRP. In addition, this study observed a significant weak inverse relationship between vitamin D and CRP in the GDM group, as seen in Figure 5; 
Fig. 6. A scatterplot showing a weak inverse relationship between vitamin D and zinc.

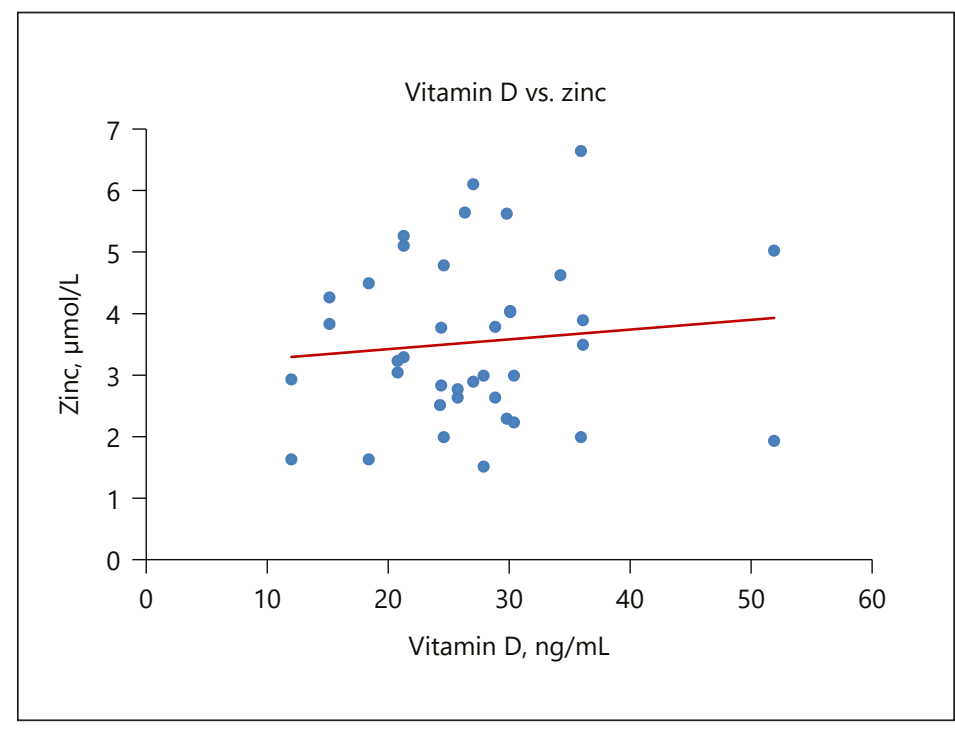

this is supported by the work of Burris et al. [44]. CRP at mid-pregnancy correlates with GDM and inflammation is suggestive of the disease development [68]. The probable mechanism by which vitamin D interferes with the inflammatory process may be the suppression of nuclear factor kappa- $\beta$ by vitamin $D$ that brings about inhibition of endogenous CRP synthesis [57]. Intake of vitamin D supplements in healthy pregnant women has been linked to significant decreases in serum CRP levels. The anti-inflammatory effect of vitamin $D$ in diabetes has been reported in some studies [69].The anti-inflammatory effect of vitamin D might be that the active form of vitamin D decreases the expression of pro-inflammatory cytokines such as IL-6, IL-1, and TNF- $\alpha$ involved in insulin resistance [70].

Decreased serum zinc was observed in the GDM group compared with controls, similar to the study of Shams et al. [71]. Also in the present study, there was a significant positive relationship between serum vitamin D and zinc levels in the GDM group, as shown in Figure 6. Zinc is involved in the synthesis, storage, and secretion of monomeric insulin [71], as well as conversion to a dimeric form for storage and secretion as crystalline insulin [72]. Zinc element may have a key role in improving peripheral insulin sensitivity through potentiating insulinstimulated glucose transport [73]. All these show that zinc is essential in insulin action and carbohydrate metabolism. Additionally, zinc is a cofactor of antioxidant enzymes such as superoxide dismutase (SOD) and catalase, and is involved in the protection of pancreatic $\beta$ cells and insulin against free radicals [74].

The vitamin D receptor binds zinc, and the activity of vitamin D-dependent genes in cells is influenced by intracellular zinc concentrations; in essence, zinc aids in the intracellular roles of vitamin $\mathrm{D}$.

In conclusion, this study supports other studies stating that hypovitaminosis D in pregnancy complicated with GDM impacts negatively not only on glucose, but also on serum ferritin, hsCRP, and zinc. This study suggests that hypovitaminosis D in GDM might not just be a pathological feature but a causative factor in the development of GDM because of its relationship with important metabolic indices involved in the pathogenesis of GDM. Vitamin D plays an important role in preventing inflammation and maintaining glucose homeostasis. Further studies that will explore the link between vitamin D status and the development of gestational diabetes with emphasis on other metabolic indices and genetic markers are very important. 


\section{Recommendation}

The nutritional state before and during pregnancy affects general maternal health and fetal growth during pregnancy. Vitamin D, which has its source limited not only to sunlight but to fatty fish oil, egg yolk, and mushroom, is very important in all stages of pregnancy; its functions are numerous and cannot be overemphasized. Diets and supplements rich in vitamin $\mathrm{D}$ are encouraged before, during, and after conception.

\section{Study Limitation}

The small sample size is the major limitation of this study due to lack of funds. However, further study with a large sample size is encouraged to establish the relationship between vitamin D and metabolic indices in GDM in Nigeria, as reported in the present study.

\section{Acknowledgments}

We acknowledge all the doctors in the Chemical Pathology Department, UCH Ibadan, and all the lecturers in the Science Laboratory Department, Ekiti State University, Ado Ekiti, for their support during the research work.

\section{Statement of Ethics}

Written informed consent was duly signed by all participants. The study protocol was approved by the research institute's committee on human research. Ethical clearance was issued by the Institute of Medical Research and Training (IMRAT) in the University College Hospital, Ibadan, Nigeria.

\section{Disclosure Statement}

The authors have no conflicts of interest to declare.

\section{Funding Sources}

This research work was funded by the authors.

\section{Author Contributions}

Ayobola A. Sonuga designed the research work and wrote the first protocol and the final manuscript. Oyebola O. Sonuga performed all laboratory analysis and read the final manuscript.

\section{References}

1 Camelo Castillo W, Boggess K, Stürmer T, Brookhart MA, Benjamin DK Jr, Jonsson Funk M. Trends in glyburide compared with insulin use for gestational diabetes treatment in the United States, 2000-2011. Obstet Gynecol. 2014 Jun;123(6):1177-84.

2 American Diabetes Association. 2. Classification and Diagnosis of Diabetes: Standards of Medical Care in Diabetes-2018. Diabetes Care. 2018 Jan;41(Suppl 1):S13-27.

\section{Karger's}


3 Mwanri AW, Kinabo J, Ramaiya K, Feskens EJ. Gestational diabetes mellitus in sub-Saharan Africa: systematic review and metaregression on prevalence and risk factors. Trop Med Int Health. 2015 Aug;20(8):983-1002.

4 Zhu Y, Zhang C. Prevalence of gestational diabetes and risk of progression to type 2 diabetes: a global perspective. Curr Diab Rep. 2016 Jan;16(1):7.

5 Kuti MA, Abbiyesuku FM, Akinlade KS, Akinosun OM, Adedapo KS, Adeleye JO, et al. Oral glucose tolerance testing outcomes among women at high risk for gestational diabetes mellitus. J Clin Pathol. 2011 Aug;64(8):718-21.

6 Clifton-Bligh RJ, McElduff P, McElduff A. Maternal vitamin D deficiency, ethnicity and gestational diabetes. Diabet Med. 2008 Jun;25(6):678-84.

7 Janus A, Szahidewicz-Krupska E, Mazur G, Doroszko A. Insulin resistance and endothelial dysfunction constitute a common therapeutic target in cardiometabolic disorders. Mediators Inflamm. 2016;2016: 3634948.

8 Zhang C, Tobias DK, Chavarro JE, Bao W, Wang D, Ley SH, et al. Adherence to healthy lifestyle and risk of gestational diabetes mellitus: prospective cohort study. BMJ. 2014 Sep;349:g5450.

9 Burris HH, Camargo CA Jr. Vitamin D and gestational diabetes mellitus. Curr Diab Rep. 2014 Jan;14(1):451-61.

10 Getahun D, Ananth CV, Peltier MR, Salihu HM, Scorza WE. Changes in prepregnancy body mass index between the first and second pregnancies and risk of large-for-gestational-age birth. Am J Obstet Gynecol. 2007 Jun; 196(6):530.e1-8.

11 Santoro D, Gitto L, Ferraro A, Satta E, Savica V, Bellinghieri G. Vitamin D status and mortality risk in patients with chronic kidney disease. Ren Fail. 2011;33(2):184-91.

12 Pickup JC. Inflammation and activated innate immunity in the pathogenesis of type 2 diabetes. Diabetes Care. 2004 Mar;27(3):813-23.

13 Bo S, Signorile A, Menato G, Gambino R, Bardelli C, Gallo ML, et al. C-reactive protein and tumor necrosis factoralpha in gestational hyperglycemia. J Endocrinol Invest. 2005 Oct;28(9):779-86.

14 Maged AM, Moety GA, Mostafa WA, Hamed DA. Comparative study between different biomarkers for early prediction of gestational diabetes mellitus. J Matern Fetal Neonatal Med. 2014 Jul;27(11):1108-12.

15 Hara T, Takeda TA, Takagishi T, Fukue K, Kambe T, Fukada T. Physiological roles of zinc transporters: molecular and genetic importance in zinc homeostasis. J Physiol Sci. 2017 Mar;67(2):283-301.

16 Yang HK, Lee SH, Han K, Kang B, Lee SY, Yoon KH, et al. Lower serum zinc levels are associated with unhealthy metabolic status in normal-weight adults: The 2010 Korea National Health and Nutrition Examination Survey. Diabetes Metab. 2015 Sep;41(4):282-90.

17 Jayawardena R, Ranasinghe P, Galappatthy P, Malkanthi R, Constantine G, Katulanda P. Effects of zinc supplementation on diabetes mellitus: a systematic review and meta-analysis. Diabetol Metab Syndr. 2012 Apr;4(1):13.

18 Hadwan MH, Almashhedy LA, Alsalman AR. Study of the effects of oral zinc supplementation on peroxynitrite levels, arginase activity and NO synthase activity in seminal plasma of Iraqi asthenospermic patients. Reprod Biol Endocrinol. 2014 Jan;12(1):1.

19 Korkmaz-Icöz S, Atmanli A, Radovits T, Li S, Hegedüs P, Ruppert M, et al. Administration of zinc complex of acetylsalicylic acid after the onset of myocardial injury protects the heart by upregulation of antioxidant enzymes. J Physiol Sci. 2016 Mar;66(2):113-25.

20 Skalny AA, Tinkov AA, Medvedeva YS, Alchinova IB, Karganov MY, Skalny AV, et al. Effect of short-term zinc supplementation on zinc and selenium tissue distribution and serum antioxidant enzymes. Acta Sci Pol Technol Aliment. 2015 Jul-Sep;14(3):269-76.

21 Hentze MW, Muckenthaler MU, Andrews NC. Balancing acts: molecular control of mammalian iron metabolism. Cell. 2004 Apr;117(3):285-97.

22 Ganz T. Systemic iron homeostasis. Physiol Rev. 2013 0ct;93(4):1721-41.

23 Gillum RF: Association of serum ferritin and cardiovascular risk factors: a cross-sectional analysis of data from the third National Health and Nutrition Examination Survey [article online]. ISPUB.com. 2005. Available from: http://ispub.com/IJE/2/1/6069.

24 Fernández-Real JM, López-Bermejo A, Ricart W. Cross-talk between iron metabolism and diabetes. Diabetes. 2002 Aug;51(8):2348-54.

25 Lao TT, Ho LF. Impact of iron deficiency anemia on prevalence of gestational diabetes mellitus. Diabetes Care. 2004 Mar; 27(3):650-6.

26 Jiang R, Manson JE, Meigs JB, Ma J, Rifai N, Hu FB. Body iron stores in relation to risk of type 2 diabetes in apparently healthy women. JAMA. 2004 Feb;291(6):711-7.

27 Xinhua C, Theresa OS, Peter S T. Association of Elevated Serum Ferritin Levels and the Risk of Gestational Diabetes Mellitus in Pregnant Women. The Camden Study. Diabetes Care. 2006 May;29(5):1077-82.

28 Sonuga AA, Asaolu MF,Oyeyemi AO, Sonuga 00. Effects of Vitamin D3 Supplementation on Antioxidant Status and Lipid Peroxidation Product in Preeclamptic Women. Open Access J Gynecol. 2019;4(1). Available from: https://medwinpublishers.com/OAJG/OAJG16000169.pdf.

29 Bikle DD. Vitamin D metabolism, mechanism of action, and clinical applications. Chem Biol. 2014 Mar;21(3): 319-29.

30 Pleskačová A, Bartáková V, Pácal L, Kuricová K, Bělobrádková J, Tomandl J, et al. Vitamin D Status in Women with Gestational Diabetes Mellitus during Pregnancy and Postpartum. BioMed Res Int. 2015;2015:260624.

31 Wen J, Hong Q, Zhu L, Xu P, Fu Z, Cui X, et al. Association of maternal serum 25-hydroxyvitamin D concentrations in second and third trimester with risk of gestational diabetes and other pregnancy outcomes. Int J Obes. 2017 Apr;41(4):489-96. 
32 Daniel WW. Biostatistics: A Foundation for Analysis in the Health Sciences. 7th ed. New York: John Wiley \& Sons; 1999.

33 Trinder P. Determination of Glucose in Blood Using Glucose Oxidase with an Alternative Oxygen Acceptor. Ann Clin Biochem. 1969;6:24.

34 Nakagawa S, Nakayama H, Sasaki T, Yoshino K, Yu YY. A simple method for the determination of serum free insulin levels in insulin-treated patients. Diabetes. 1973 Aug;22(8):590-600.

35 Burtis CA, Ashwood ER. Tietz textbook of clinical chemistry. 3rd ed. Philadelphia (PA): Saunders; 1999.

36 Molina-López J, Del Pozo EP, Florea DI, Fernadez C, Osso BQ, Zalewska M, Krizkova S, Heger Z, Kizek R, Adam V. Nutritional and methodological perspectives of zinc ions and complexes - physiological and pathological states. Int J Electrochem Sci. 2016;11:4470-96.

37 Garton AL, Gupta VP, Christophe BR, Connolly ES Jr. Biomarkers of Functional Outcome in Intracerebral Hemorrhage: Interplay between Clinical Metrics, CD163, and Ferritin. J Stroke Cerebrovasc Dis. 2017 Aug; 26(8):1712-20.

38 Holick MF, Chen TC. Vitamin D deficiency: a worldwide problem with health consequences. Am J Clin Nutr. 2008 Apr;87(4):1080S-6S.

39 Matthews DR, Hosker JP, Rudenski AS, Naylor BA, Teacher DF, Tumer RC. Homeostasis model assessment: Insulin resistance and beta cell function from fasting plasma glucose and insulin concentration in man. Diabetologia. 1985;28:412-9.

40 Zar JH. Biostatistical Analysis. 2nd ed. Englewood Cliffs: Prentice-Hall, Inc.; 1984. 718 pp.

41 Haugen M, Brantsæter AL, Winkvist A, Lissner L, Alexander J, Oftedal B, et al. Associations of pre-pregnancy body mass index and gestational weight gain with pregnancy outcome and postpartum weight retention: a prospective observational cohort study. BMC Pregnancy Childbirth. 2014 Jun;14(1):201.

42 Gaillard R, Durmuș B, Hofman A, Mackenbach JP, Steegers EA, Jaddoe VW. Risk factors and outcomes of maternal obesity and excessive weight gain during pregnancy. Obesity (Silver Spring). 2013 May;21(5):104655.

43 Chu SY, Callaghan WM, Kim SY, Schmid CH, Lau J, England LJ, et al. Maternal obesity and risk of gestational diabetes mellitus. Diabetes Care. 2007 Aug;30(8):2070-6.

44 Burris CA, Ashwood ER, Burns DE. Tietz Textbook of Clinical Chemistry and Molecular Diagnostics. 5th ed. St. Louis: Elsevier Saunders; 2012.

45 Fatemeh H, Mohammad T, Nahid S,Mohammad H, Elham J. Comparison of Serum Levels of Vitamin D and Inflammatory Markers between Women with Gestational Diabetes Mellitus and Healthy Pregnant Control. Family Reprod Health. 2016;10(1):1-8.

46 Maghbooli Z, Hossein-Nezhad A, Karimi F, Shafaei AR, Larijani B. Correlation between vitamin D3 deficiency and insulin resistance in pregnancy. Diabetes Metab Res Rev. 2008 Jan-Feb;24(1):27-32.

47 Wang O, Nie M, Hu YY, Zhang K, Li W, Ping F, et al. Association between vitamin D insufficiency and the risk for gestational diabetes mellitus in pregnant Chinese women. Biomed Environ Sci. 2012 Aug;25(4):399406.

48 El Lithy A, Abdella RM, El-Faissal YM, Sayed AM, Samie RM. The relationship between low maternal serum vitamin D levels and glycemic control in gestational diabetes assessed by HbA1c levels: an observational cross-sectional study. BMC Pregnancy Childbirth. 2014 Oct;14(1):362.

49 Lau SL, Gunton JE, Athayde NP, Byth K, Cheung NW. Serum 25-hydroxyvitamin D and glycated haemoglobin levels in women with gestational diabetes mellitus. Med J Aust. 2011 Apr;194(7):334-7.

50 Bland R, Markovic D, Hills CE, Hughes SV, Chan SL, Squires PE, et al. Expression of 25-hydroxyvitamin D3-1 $\alpha$ hydroxylase in pancreatic islets. J Steroid Biochem Mol Biol. 2004 May;89-90(1-5):121-5.

51 Von Hurst PR, Welma Stonehouse W, Coad J. Vitamin D supplementation reduces insulin resistance in South Asian women living in New Zealand who are insulin resistant and vitamin D deficient - a randomised, placebocontrolled trial. Br J Nutr. 2010 Feb;103(4):549-55.

52 Mørkrid K, Jenum AK, Sletner L, Vårdal MH, Waage CW, Nakstad B, et al. Failure to increase insulin secretory capacity during pregnancy-induced insulin resistance is associated with ethnicity and gestational diabetes. Eur J Endocrinol. 2012 Oct;167(4):579-88.

53 Qiu C, Sorensen TK, Luthy DA, Williams MA. A prospective study of maternal serum C-reactive protein (CRP) concentrations and risk of gestational diabetes mellitus. Paediatr Perinat Epidemiol. 2004 Sep;18(5):377-84.

54 Dunlop TW, Väisänen S, Frank C, Molnár F, Sinkkonen L, Carlberg C. The human peroxisome proliferator-activated receptor $\delta$ gene is a primary target of $1 \alpha, 25$-dihydroxyvitamin D3 and its nuclear receptor. J Mol Biol. 2005 Jun;349(2):248-60.

55 Maestro B, Campión J, Dávila N, Calle C. Stimulation by 1,25-dihydroxyvitamin D3 of insulin receptor expression and insulin responsiveness for glucose transport in U-937 human promonocytic cells. Endocr J. 2000 Aug; 47(4):383-91.

56 Björklund A, Lansner A, Grill VE. Glucose-induced [Ca2+]i abnormalities in human pancreatic islets: important role of overstimulation. Diabetes. 2000 Nov;49(11):1840-8.

57 Chen N, Wan Z, Han SF, Li BY, Zhang ZL, Qin LQ. Effect of vitamin D supplementation on the level of circulating high-sensitivity C-reactive protein: a meta-analysis of randomized controlled trials. Nutrients. 2014 Jun;6(6): 2206-16.

58 Nemeth E, Tuttle MS, Powelson J, Vaughn MB, Donovan A, Ward DM, et al. Hepcidin regulates cellular iron efflux by binding to ferroportin and inducing its internalization. Science. 2004 Dec;306(5704):2090-3. 
59 Green A, Basile R, Rumberger JM. Transferrin and iron induce insulin resistance of glucose transport in adipocytes. Metabolism. 2006 Aug;55(8):1042-5.

60 Dignass A, Farrag K, Stein J. Limitations of Serum Ferritin in Diagnosing Iron Deficiency in Inflammatory Conditions. Int J Chronic Dis. 2018 Mar;2018:9394060.

61 Malczewska-Lenczowska J, Sitkowski D, Surała O, Orysiak J, Szczepańska B, Witek K. The association between Iron and vitamin D status in female elite athletes. Nutrients. 2018 Jan;10(2):E167.

62 Smith EM, Tangpricha V. Vitamin D and anemia: insights into an emerging association. Curr Opin Endocrinol Diabetes Obes. 2015 Dec;22(6):432-8.

63 Sim JJ, Lac PT, Liu IL, Meguerditchian SO, Kumar VA, Kujubu DA, et al. Vitamin D deficiency and anemia: a crosssectional study. Ann Hematol. 2010 May;89(5):447-52.

64 Rudnicki PM, Mølsted-Pedersen L. Effect of 1,25-dihydroxycholecalciferol on glucose metabolism in gestational diabetes mellitus. Diabetologia. 1997 Jan;40(1):40-4.

65 Reichetzeder C, Chen H, Föller M, Slowinski T, Li J, Chen YP, et al. Maternal vitamin D deficiency and fetal programming-lessons learned from humans and mice. Kidney Blood Press Res. 2014;39(4):315-29.

66 Rota S, Yildirim B, Kaleli B, Aybek H, Duman K, Kaptanoğlu B. C-reactive protein levels in non-obese pregnant women with gestational diabetes. Tohoku J Exp Med. 2005 Aug;206(4):341-5.

67 Cruz NG, Sousa LP, Sousa MO, Pietrani NT, Fernandes AP, Gomes KB. The linkage between inflammation and Type 2 diabetes mellitus. Diabetes Res Clin Pract. 2013 Feb;99(2):85-92.

68 Eftekhari MH, Akbarzadeh M, Dabbaghmanesh MH, Hasanzadeh J. Impact of treatment with oral calcitriol on glucose indices in type 2 diabetes mellitus patients. Asia Pac J Clin Nutr. 2011;20(4):521-6.

69 Liu W, Zhang L, Xu HJ, Li Y, Hu CM, Yang J, Sun MY. The Anti-Inflammatory Effects of Vitamin D in Tumorigenesis. Int J Mol Sci. 2018;19(9):2736.

70 Chagas CE, Borges MC, Martini LA, Rogero MM. Focus on vitamin D, inflammation and type 2 diabetes. Nutrients. 2012 Jan;4(1):52-67.

71 Shams B, Afshari E, Tajadini M, Keikha M, Qorbani M, Heshmat R, et al. The relationship of serum vitamin D and Zinc in a nationally representative sample of Iranian children and adolescents: the CASPIAN-III study. Med J Islam Repub Iran. 2016 Oct;30:430.

72 Ward CW, Lawrence MC. Landmarks in insulin research. Front Endocrinol (Lausanne). 2011 Nov;2:76.

73 Tang X, Shay NF. Zinc has an insulin-like effect on glucose transport mediated by phosphoinositol-3-kinase and Akt in 3T3-L1 fibroblasts and adipocytes. J Nutr. 2001 May;131(5):1414-20.

74 Chausmer AB. Zinc, insulin and diabetes. J Am Coll Nutr. 1998 Apr;17(2):109-15. 